\title{
HUSSERL E A ESPECIFICIDADE DA VALORAÇÃO
}

\section{HUSSERL AND THE ESPECIFICITY OF VALUATION}

\author{
DARIO TEIXEIRA ${ }^{1}$ \\ (UNIRIO/Brasil)
}

\begin{abstract}
RESUMO
Pretendemos mostrar que a crítica de Husserl ao psicologismo axiológico o levará, por fim, a discernir boas razões fenomenológicas para diferenciar (sob a forma de uma auto-crítica a sua posição inicial), por um lado, a valoração e, por outro, os atos concernentes ao sentimento, desejo e vontade com os quais aquela é comumente identificada.

Palavras-chave: Axiologia. Psicologismo. Fenomenologia. Husserl.
\end{abstract}

\begin{abstract}
This paper argues that Husserl's critical reflexion about axiological psychologism comes eventually to discern very effective phenomenological reasons to distinguish the evaluation from the sentiment, desire or will with which it is commonly identified.
\end{abstract}

Keywords: Axiology. Psychologism. Phenomenology. Husserl.

Husserl é um filósofo particularmente célebre por ter combatido com boas razões toda forma de relativismo cético como sendo autocontraditória. Nesse sentido, menciona-se invariavelmente a crítica de Husserl ao naturalismo cientificista, que foi dominante na virada do século XIX para o $\mathrm{XX}$ e que, na filosofia, destacou-se mais sob a forma do assim chamado "psicologismo lógico", que pretendeu reduzir as significações e suas formas, bem como as leis lógicas, a meras generalizações indutivas obtidas por abstração sobre os processos psíquicos reais da mente humana tal como estudados pela ciência psicológica. Contra esse psicologismo lógico, como se sabe, Husserl fez valer a distinção entre existência real e validez ideal, entre fato e essência, entre conhecimento empírico e conhecimento ideal ou formal; e ele fez isso (em meio ao cientificismo soberbo da época) para tentar manter vivo o antigo programa socrático-platônico de emancipar-nos da obscuridade dos meros fatos e elevar-nos até a clarividente compreensão do sentido da experiência.

O que, porém, se menciona com bem menos frequência é que o programa husserliano de superação do relativismo cético não combateu apenas este "psicologismo lógico" que reduzia o sentido de ser ao mero fato de existir empiricamente ${ }^{2}$, mas antes, o combate de Husserl precisou voltar-se também contra uma outra forma de psicologismo, a saber, contra um tipo de psicologismo que, no entanto, é ainda hoje tão difusamente aceito que esse próprio fato de sua aceitação como posição-padrão pré-reflexiva até ajuda a entender porque então a crítica de Husserl a ele é tão poucas vezes mencionada; falamos aqui do que pode ser chamado de "psicologismo axiológico" e que se caracteriza por reduzir o sentido dos valores ao mero fato das nossas preferências empíricas, 
por exemplo, dos nossos sentimentos de aprovação ou desaprovação. Com efeito, esse psicologismo com respeito a valores é até mais antigo que o psicologismo lógico do final do século XIX, pois é irmão gêmeo da operação teórica que instaurou as ciências modernas, nomeadamente, a operação de distinguir realmente qualidades primárias da própria realidade (tal como extensão, figura, movimento) e qualidades secundárias que seriam antes concernentes a nossas reações subjetivas à realidade e, assim, que seriam meras aparências relativas a nossos modos de sentir; entre tais qualidades secundárias contava-se então, por exemplo, não só cores ou sabores, mas também valores tais como beleza ou bondade. Para ficar claro que não falamos aqui de um mero espantalho teórico ou de uma teoria-de-ninguém, cabe lembrar ao menos uma das mais célebres tomadas de posição em favor do que chamamos de "psicologismo axiológico", nomeadamente, a de David Hume.

Hume não só aderiu a essa posição, mas até teve o mérito de dar a ela forma sistemática ao se propor a "fundamentar" a moralidade sobre as paixões ou sentimentos, e até por isso é contra Hume que Husserl argumentará mais diretamente em sua crítica ao psicologismo axiológico. De todo modo, Hume ainda é considerado, até nos nossos dias, como o grande herói de uma teoria dos valores sem valores, isto é, uma teoria que reduz valores a meras preferências sempre subjetivas, ainda que possam ser coletivamente subjetivas por força tanto da natureza humana quanto das pressões do meio cultural que são capazes de garantir uma uniformização contingente de nossos modos de sentir e, assim, são capazes de dar uma regularidade a nossos sentimentos de aprovação, que determinaria que algo é bom, e de desaprovação, que determinaria que algo é ruim ${ }^{3}$. Nesse sentido, em uma passagem célebre do seu Tratado sobre a Natureza Humana (1739-1740), Hume afirma o seguinte:

\footnotetext{
Tome qualquer ação considerada viciosa, por exemplo, o assassínio deliberado. Lance sobre essa ação todas as luzes para examiná-la e veja se você pode encontrar aquele fato ou existência real que você chama de vício. Como quer que você considere isso, você encontra aí apenas certas paixões, motivos, volições e pensamentos. Não há qualquer fato nesse caso. $\mathrm{O}$ vício lhe escapa inteiramente por todo o tempo em que você considera o objeto [sc. a ação de assassinar]. Você nunca pode descobrir o vício até que você volte sua reflexão para o que se encontra em seu próprio peito e descubra um sentimento (sentiment) de desaprovação que emerge em você frente a essa ação. Aqui está o fato procurado, mas tratase então de objeto do afeto (feeling) e não da razão. Ele se encontra em você mesmo e não no objeto. Sendo assim, quando você afirma ser vicioso qualquer ação ou caráter, você não diz com isso nada mais do que o seguinte: que, de acordo com a conformação de sua própria natureza pessoal, você tem um sentimento de censura (blame) advindo da contemplação da ação ou do caráter da pessoa em questão (HUME, 1987; III, 1, 1).
} 
Nessa passagem encontramos todos os elementos centrais para a formulação de uma teoria do valor na acepção do "psicologismo axiológico". Cabe-nos aqui justamente expor e analisar as tomadas de posição de Husserl frente a essa pretensão de que valores reduzir-se-iam a fatos psíquicos, na medida em que, supostamente, as próprias valorações não seriam mais do que modos de expressão de preferências subjetivas, quer individuais quer coletivas. Fique claro, de saída, que não se trata, porém, de erguer a pretensão de que Husserl seria um puro e simples objetivista com respeito a valores, como se ele postulasse que valores fossem objetos ideais existindo em si e por si independentemente de nossa consciência deles ou também que Husserl acredite que valores se encontrem simplesmente nas próprias coisas como mais uma dentre suas propriedades determinantes. Na verdade, desde a perspectiva fenomenológica, são completamente louváveis as abordagens (como a encontrada em Hume) que correlacionam objetalidades (no caso: valores) aos modos de consciência unicamente nos quais eles podem nos ser dados de algum modo (no caso: as vivências de valoração). Porém, esse remontar reflexivo à vida intencional da subjetividade que é constituinte do sentido dos diferentes tipos de objetalidade, em suma, essa atitude fenomenológica de análise descritiva dos modos de dar-se das objetalidades para a consciência não pode de modo algum significar (como ocorre em Hume) uma dissolução da objetividade dessas objetalidades de nossa experiência (como se passa nos programas reducionistas e eliminativistas). Husserl se pronuncia exatamente nesse sentido contra a abordagem tanto objetivista quanto psicologista em relação a valores; em 1908, ele afirma isso nos seguintes termos:

[Há] objetalidades que têm valor, mas isso não quer dizer que resida nelas próprias quaisquer predicados tais como 'bom', 'belo', etc. (...). Seria uma evidente metabasis [objetivista] querer deduzir os predicados de valor a partir de meros 'predicados teóricos' [que apenas fixam as determinações naturais que residem no próprio objeto]. Obviamente, temos também de resistir à tentação psicologista de considerar valores como predicados psíquicos, como objetos psicológicos, e com isso fazê-los evaporar psicologisticamente. Decerto essa tentação psicologista está intimamente conectada com as dificuldades que nos movem nesse assunto. Com efeito, ao perguntarmos pela constituição [na consciência] daquelas objetalidades que são valores, nos defrontamos então com a função enigmática dos atos valorativos (HUSSERL, 1908/09; p.283-84) ${ }^{4}$.

Vê-se nessa passagem que, ao rejeitar tanto o objetivismo quanto o psicologismo acerca dos valores, Husserl imediatamente reconhece que seu trabalho precisará, portanto, começar bem do início e pelo mais básico, a saber, esclarecendo reflexivamente a "função enigmática dos atos valorativos". Pretendemos mostrar na sequência que Husserl mudará significativamente de posição no curso dessas suas reflexões, e isso porque sua concepção inicial da especificidade dos atos 
valorativos (brentaniana em sua identificação de tais atos com as moções do ânimo, aliás, com o gostar, o desejar e o querer) se revelará como perigosamente comprometida com aquele próprio psicologismo axiológico que ele justamente pretendia criticar e superar em favor de uma ciência axiológica como fundamento das ciências normativas.

Quanto a isso, nossos resultados podem ser assim sumarizados: inicialmente (desde as suas Investigações Lógicas de 1900/01 até suas Preleções sobre Ética e Axiologia de 1914) ${ }^{5}$, Husserl considera a vivência concreta de valoração como tendo uma estrutura bipartite; ela envolvia: (i) um ato objetivante que representa um objeto ou estado de coisas e (ii) um ato apreciativo de tomar posição interessada (subjetivamente) com respeito à objetalidade posta e, assim, constituí-la como objeto-agradável, objeto-desejável, objeto-querível (com o perdão do neologismo), o que significava então para Husserl o mesmo que objeto-valioso. Mais tarde (expressamente em suas observações críticas a suas Preleções de 1914), Husserl revisa essa sua posição e propõe uma estrutura tripartite na descrição da vivência concreta de valoração, a saber: (i) um ato objetivante que representa um objeto puro e simples, (ii) um ato de tomada de posição valorativa que constitui o objeto representado como objeto-valioso, e isso sem relação com as moções de ânimo; por fim, (iii) um ato interessado de apreciação do objeto-valioso como sendo, segundo as moções do ânimo, ou bem agradável ou não, desejável ou não, querível ou não. Com isso fica claro que, em sua reflexão mais madura, Husserl entende que não são nossos atos de gostar, desejar, querer que decidem pelo valor do objeto, mas antes tais atos já pressupõem um objeto-valioso pelo qual se interessarem, e tal objeto-valioso precisa ser então constituído por uma ato específico de valoração que (para não incorrermos em circularidade) não pode depender de moções do ânimo, ainda que possa, e até precise, pressupor atos de representação que ponha um objeto puro e simples à disposição do ato de valoração.

(I)

\section{VALORAÇÃO COMO ATO NÃO-OBJETIVANTE}

Retomando lições da análise da consciência empreendida desde Descartes e depuradas pela psicologia descritiva de seu mestre Brentano, Husserl caracteriza a consciência em sentido estrito como vivência intencional, isto é, vivência do sujeito referida de maneira determinada a algo de determinado, e usa o termo "ato" para designar esse tipo de vivência de consciência determinada de algo determinado. Nesse gênero das vivências intencionais caracterizadas por sua referência a objetalidades, Husserl discerne diferentes espécies de consciência, e isso segundo os modos 
específicos como cada espécie de consciência efetua sua referência a algo.

De saída, podemos dizer que Husserl distingue basicamente duas espécies de atos, nomeadamente, os atos objetivantes, que se referem a algo à maneira de uma tomada de posição com respeito ao ser ou não-ser de seu objeto, e os atos não-objetivantes, isto é, cuja referência a algo não consiste em uma tomada de posição quanto à existência ou não de certo objeto. Os atos objetivantes, que podem ser chamados genericamente de "representações", são mais basicamente os atos de perceber e de julgar: Quem percebe esta página deste texto toma-a como um objeto determinado existente; quem julga que Goiânia é a capital de Goiais toma isso como um fato determinado vigente. Assim, a característica básica específica desses atos objetivantes ou representações é sua referência a algo determinado sob o modo da crença no seu ser (doxa).

Os atos não-objetivantes, por sua vez, são não-objetivantes porque obviamente não fazem isso. Eles se referem sim a algo determinado e o fazem decerto de uma maneira determinada, mas aquilo a que se referem propriamente não é um objeto puro e simples, bem como seu modo específico de referência não consiste numa crença na existência de um tal objeto. Sob esse título de "atos não-objetivantes", Husserl reúne de saída tudo aquilo que Brentano chamava mais genericamente de "Gemütsbewegungen" ou, como traduzirei, "moções do ânimo". Nessa classe, encontram-se mais exemplarmente os sentimentos (tais como alegria e ódio), os desejos (tais como aspiração e expectativa) e as vontades (sob as formas de resolução-de-agir ou de intento-em-ação). Mas, cabe perguntar: se elas não são representações, então (1) o que faz então com que essas moções do ânimo sejam caracterizáveis como vivências intencionais e, sobretudo, (2) o que faz com que elas sejam caracterizáveis como um modo de consciência específico diferente da espécie caracterizada como ato objetivante ou representação?

Quanto à primeira questão, o que basicamente faz as moções do ânimo serem intencionais é certa relação que elas mantêm para com as representações, a saber, a relação de fundação unilateral. Uma fundação unilateral é tal que se algo A está fundado unilateralmente sobre algo B, então A depende de B, mas não inversamente. Assim, as moções do ânimo (sentimentos, desejos, vontades) são fundadas sobre representações no sentido de que elas dependem de representações para serem, enquanto representações, por sua vez, não precisam de moções do ânimo para serem. Mais concretamente, posso identificar uma representação tal como o juízo de que o dia está ensolarado sem que precise identificar simultaneamente qualquer vivência tal como, digamos, a alegria; ou seja, simplesmente julgo sem ter uma disposição de ânimo determinada com respeito ao fato judicado. Por outro lado, se uma moção do ânimo tal como a alegria é para ser um ato ou vivência intencional ${ }^{6}$, isso é apenas porque uma representação de base lhe apresenta um objeto ou estado de 
coisas com o que se alegrar. Quer dizer, só identificamos uma vivência intencional de alegria, na medida em que também identificamos uma vivência intencional de representação que põe um objeto com o qual o ânimo estabelece então sua relação própria. Que tipo de relação é essa? Aqui, tocamos na segunda questão formulada antes, vale lembrar: o que faz com que moções do ânimo sejam caracterizáveis como um modo de consciência específico diferente da espécie caracterizada como representação?

Quanto a essa segunda questão, ela nos leva diretamente para nosso tema aqui, pois será em resposta à pergunta acerca do tipo de relação que as moções do ânimo mantêm com os objetos que Husserl destacará que se trata aí de um modo específico de referência a algo, a saber, a referência não ao ser ou não ser do objeto, mas antes a referência ao valor ou desvalor do objeto, o que faz com que as moções do ânimo, enquanto tais, devam ser caracterizadas como atos de valoração. Retomando nosso exemplo, a alegria com o dia ensolarado se refere a esse fato, mas não à maneira da mera representação do ser ou não-ser desse fato determinado; bem ao contrário, a alegria dá esse fato como posto pela representação judicativa e, por sua vez, se refere então ao fato de maneira interessada no que ele eventualmente tem de bom ou ruim; no exemplo, interessada no que o fato tem de regojizante para o ânimo. Com repeito a outras moções do ânimo tais como desejar e querer, pode-se dizer o mesmo. Se, por exemplo, uma representação conjectural põe como possível que a continuidade das políticas sociais de inclusão resolvam no prazo de mais dez anos o problema da distribuição da renda no Brasil, então, fundado sobre tal representação, pode-se estar motivado a desejar a continuidade das políticas sociais de inclusão no Brasil ou mesmo a querer agir (por exemplo, votando) em favor da continuidade das políticas sociais de inclusão no Brasil. Em ambos os casos, toma-se uma posição interessada no que o fato (posto pela representação como sendo real, possível ou provável) tem de valioso ou de desvalor. Tudo isso pode ser aprendido diretamente da Investigação V das Logische Untersuchungen de Husserl e, mais diretamente, do seu §15 dedicado ao tema do gênero de ato das moções de ânimo.

Como primeiro resultado então dessa nossa análise, podemos dizer que há atos especificamente valorativos que se fundam em atos especificamente representacionais. Isto é, por contraste com o modo específico como a representação refere-se ao ser ou não-ser de objetalidades determinadas, chegamos a identificar outro grupo de vivências intencionais ou atos que se referem a objetalidades representadas, mas de uma maneira nova ou não-representacional, a saber, de uma maneira especificamente valorativa. Nesse sentido, ainda em suas Preleções de 1908/9, Husserl reafirma essa caracterização geral da valoração nos seguintes termos: 
Não apenas representar (perceber, julgar, etc.) é 'consciência', mas valorar também é 'consciência' e o é enquanto consciência valorante e não enquanto consciência percipiente ou pensante. Enquanto consciência valorante ela deve ser constituinte da objetalidade e, com efeito, constituinte da objetalidade que essencialmente é pertinente a ela [sc. a objetalidade do objeto-valioso e não do mero objeto puro e simples da representação]. (...). É inquestionável que, enquanto consciência, o valorar em suas diferentes formas como gostar, como desejar, como querer, equipara-se a atos que chamamos de perceber, pensar, conjecturar, etc., na medida em que o valorar tem seu modo especificamente diferenciado de referência a objetalidades (HUSSERL, 1908/9; p.266) ${ }^{7}$.

Nesse ponto eu diria que completamos a parte mais fácil de nossa análise, pois agora teremos de lidar com uma questão frente a qual a análise do próprio Husserl vacila e se torna mais tentativa que conclusiva. Essa questão mais difícil diz respeito àquilo que mais propriamente caracteriza a valoração enquanto tal, isto é, a questão quanto à natureza própria ou essência dessa espécie de vivência intencional chamada de valoração. Por que esse ponto é mais problemático?

\section{A VALORAÇÃO NÃO SE CONFUNDE COM AS MOÇÕES DO ÂNIMO}

Já seria um primeiro problema o fato de termos admitido, talvez com demasiada naturalidade e sem maiores esclarecimentos, que sob o título de "atos valorativos" se reúnam vivências prima facie tão diversas quanto sentimentos (v.g. agrado/desagrado ou, numa ordem superior, aprovação/desaprovação), desejos (aspirações e expectativas) e vontades (resoluções e intentos-emação). Partindo de nossas intuições mais imediatas, concedemos sem mais que essas diferentes vivências seriam todas formas de estimar o valor de algo, por exemplo, estimar algo sob a forma do apreciar o que algo tem de apreciável, do desejar o que algo tem de desejável e do querer o que algo tem de querível. A questão agora está em saber o que essa variedade de supostas formas de valoração (i.e. o valorar algo ou como apreciável ou como desejável ou como querível) tem de especificamente valorativo através dessa sua diversidade. De certa forma, eu já sugeri qual seria esse aspecto especificamente valorativo das moções do ânimo, na medida em que as tratei, por contraste com as representações, como sendo maneiras interessadas de referência a algo. Em outras palavras, essas vivências de sentimentos, de desejos e de vontades convergem todas nesse aspecto de que, por assim dizer, ponderam o que algo tem de bom para o sujeito da vivência (o bom enquanto o agradável, o desejável, o querível). Isso estabelece o chamado sentido relativo de bom 
enquanto bom para alguém ou algo, ou seja, bom segundo algum interesse. Qual o problema com isso? Bem, em suas observações críticas sobre suas Preleções de 1914, o próprio Husserl formula o problema relevante nos seguintes termos:

A questão está em saber se a afirmação: "Que [algo] A existe é bom” (ou, conforme o caso, "é ruim") é equivalente à afirmação: "Que [algo] A existe é regojizante" (ou, conforme o caso, "é desalentador"). Nas preleções, eu tratei ambas as afirmações como idênticas. Contudo, cabe refletir cuidadosamente se fiz isso com boas razões. Inclino-me recorrentemente (e agora de novo!) para a opinião de que, ao contrário, cabe separá-las (HUSSERL, 1914b, p.155. Meu grifo) ${ }^{8}$.

Parece claro nessa passagem de Husserl que ele vê razões para não identificar o valorar como bom/mau e o apreciar como agradável eaprovável ou não, como desejável ou não e como querível ou não. Em suma, Hussserl sugere agora que investiguemos numa direção que leve a reconhecer a especificidade do valorar como distinto da especificidade dessas moções do ânimo que são o prezar, desejar, querer, e isso contrariamente a suas sugestões anteriores de que a valoração seria o mero título genérico dessas diferentes moções do ânimo enquanto formas específicas do valorar. Quais seriam essas boas razões para distinguir especificamente o ato de valorar frente aos atos de prezar, desejar, querer? Para nossa sorte, o próprio Husserl indica algumas dessas razões mais patentes da impropriedade de identificar valoração e moções do ânimo.

Uma razão para rejeitar a identificação de valoração com moções do ânimo é a de que essa identificação faria com que as valorações fossem de tal natureza que sua enunciação em um juízo de valor faria com que o juízo tivesse o caráter de um juízo sobre as propensões do sujeito que seriam propriamente as vivências que então constituiriam o valor (relativo ao sujeito) do objeto como agradável, desejável, querível; ora, isso resultaria numa subjetivação do valor típica do psicologismo axiológico, o que contrariaria o próprio sentido do juízo de valor que pretende antes falar de propriedades axiológicas do próprio objeto e não tanto falar das moções de ânimo daquele que valora algo. Em um texto de 1902, em que Husserl empreende criticar a pretensão (por exemplo, de Hume) de embasar a moral sobre sentimentos, encontramos a seguinte passagem que deixa-nos ver esse reconhecimento de Husserl da dificuldade enfrentada com a presunção de validez objetiva própria às valorações ao se tentar elucidar o fenômeno do valorar por recurso somente a representações e a moções de ânimo; ele afirma: 
requer para se ter um juízo de valor; e, todavia, esse não é qualquer juízo que tenha o caráter de validez subjetiva, um juízo que [apenas] enuncia algo sobre meu sentimento nesse momento, mas antes trata-se de um juízo que pretende ter validade geral de maneira objetiva e incondicional; o juízo afirma simplesmente: Isso é certo e bom! (HUSSERL, $1902 ;$ p.388) ${ }^{9}$.

Com efeito, Husserl já aduz nesse texto de 1902 um conjunto de argumentos que são de regra em toda crítica (e não apenas a de caráter fenomenológica) dirigida à "fundamentação" da moral (e da axiologia em geral) sobre os sentimentos. Por exemplo, ele argumenta que, se o discernimento entre bem/mal e certo/errado for devido ao sentimento de aprovação/desaprovação que exprime preferências subjetivas ${ }^{10}$, então: (i) a discussão moral perderia o sentido, pois de gustibus non est disputandum; (ii) perde-se o critério objetivo de distinção do moral e imoral, bem como perde-se a possibilidade de incondicionalidade geral das normas que instituem obrigações, pois os juízos morais seriam sempre apenas relativos às preferências do sujeito da valoração, insuficientes para justificar obrigações dos agentes (p.386); (iii) não faria sentido dúvida ou engano na valoração, pois ela apenas expressaria o curso de nossas próprias moções do ânimo: o que gostamos ou não gostamos, desejamos ou não desejamos, queremos ou não queremos (p.388), e sobre isso não há grande margem para incertezas; (iv) tornar-se-ia ininteligível a possibilidade de "progresso moral" e, em lugar disso, só reconheceríamos ou bem continuidades ou bem descontinuidades no modo “normal” do sentimento de aprovar/desaprovar (p.389).

Essas são razões bastante fortes contra a abordagem bipartite da valoração em termos de representação objetivante de base e moções de ânimo sobrevenientes, mas não são ainda razões especificamente fenomenológicas, isto é, concernentes ao modo de efetuação dos atos valorativos e, correlatamente, aos modos de dar-se dos valores. Numa perspectiva propriamente fenomenológica, Husserl pondera, por sua vez, que é possível conceber o valorar independentemente do prezar, desejar, querer, ainda que talvez não o contrário; ele escreve:

Nos atos calorosos do ânimo, o valor [em questão] depende dos fins aos quais esses atos se dirigem (somente esses atos do ânimo estão voltados a um fim). Se eu valoro algo como bom, então estou justificado em alegrar-me com isso ou, conforme o caso, desejar isso [sc. a objetalidade independentemente constituída como valiosa]. Mas, posso eu dizer que todo alegrar-se, todo desejar envolve implicitamente um valorar? É aí, portanto, que cabe por em ação a investigação (HUSSERL, 1914b; p.156) ${ }^{11}$.

Claramente, Husserl pondera nessa passagem que o valorar parece estar antes em uma relação de fundação com as moções do ânimo, no sentido de que a efetuação da valoração seria o que 
motiva legitimamente uma moção do ânimo que então aprecia interessadamente o objeto-valioso, já constituído na valoração, como sendo adicionalmente agradável, desejável ou querível segundo seus fins próprios, de maneira que a valoração seria distinta e independente das moções do ânimo, assim como as moções no ânimo, ao menos quando legitimamente motivadas, seriam, por sua vez, dependentes da valoração (ou ao menos introduzem um sentido relativo de valor referido aos fins subjetivos e que não pode ser confundido com a noção de valor puro e simples).

Formulando de maneira ainda mais incisiva esse ponto, bem como acrescentando o argumento de que moções do ânimo admitem uma diferença de graus de intensidade que, porém, não é encontrável na valoração que apenas admite uma diferença de nível entre superior e inferior, Husserl pede que consideremos o seguinte exemplo:

\begin{abstract}
No valorar estético, a consciência originária do belo e do feio é o motivo ou a razão da alegria com a existência [do objeto-esteticamente-valioso], é o motivo ou razão da fascinação estética [com o belo], do repelir [o feio], etc. O tomar algo como um desvalor [estético] não é ele próprio o sentir repulsa por [esse objeto-desvalioso], bem como o tomar algo por um valor estético não é [ele próprio] o sentir-se atraído por [esse objeto-valioso]. Essas tomadas de posição quanto ao valor estético podem, no entanto, fundamentar tais sentimentos. (...). Se fico cansado [ao visitar um museu de arte], é possível que eu não sinta mais alegria ou sinta apenas uma débil alegria; contudo, a valoração não se altera. A valoração não tem de modo algum [graus de] intensidade [como na alegria], a valoração somente tem diferenças quanto à 'maior importância' ou 'menor importância' [do objetovalioso] (HUSSERL, 1914b; p.156) ${ }^{12}$.
\end{abstract}

Uma outra razão fenomenológica contra a identificação de valoração e moções do ânimo é clara na seguinte passagem das observações críticas de Husserl a suas Preleções de 1914:

\begin{abstract}
O valorar não é, contudo, qualquer perdurar e então chegar à saciedade enquanto mero modo final desse perdurar, à maneira [como se passa com a] alegria. O "estar interessado" da alegria e tristeza, da esperança e do temor, do desejar em todas as suas formas e até do querer, [todos esses modos de referência interessados são algo] de completamente distinto do valorar e de seu [modo de] tomar-em-conta-valorativamente tanto existência quanto nãoexistência [isto é, tomar valorativamente o que é posto pela representação]. As moções do ânimo são atos que, em sentido rigoroso, estão voltados para um fim ou, conforme o caso, são terminativos, mas esse não é o caso do valorar. Como cabe, porém, esclarecer essa diferença? (HUSSERL, 1914b; p.155) ${ }^{13}$.
\end{abstract}

Husserl, nessa passagem, dá uma razão direta para não identificarmos atos de valorar e moções do ânimo, a saber, o valorar, de um lado, e as moções do ânimo, de outro, são vivências 
com modos de efetuação especificamente diversos. Afinal, como ele diz, a vivência de valorar que constitui um valor não é uma vivência que dure um tanto e sacie, tal como ocorre no sentimento de alegria. Em suma, o valorar (no sentido estrito de evidenciação do valor) não vem a ser e deixa de ser da mesma maneira que uma moção do ânimo que tem um fim e perdura até chegar a uma satisfação terminativa. Nesse contexto, vale lembrar também aquela outra diferença no modo da vivência que foi mencionada há pouco (que é também, como diria um wittgensteiniano, uma diferença na "gramática" de "sentir" e "valorar"), a saber: moções do ânimo admitem diferentes graus de intensidade do próprio estado de consciência enquanto as valorações, por sua vez, não o admitem de modo algum; isso porque, quanto ao valorar constituinte do objeto como valioso, só cabe falar em diferença quanto ao nível de importância do próprio objeto-valioso.

Esse, porém, está longe de ser o fim da história, pois o próprio Husserl, na passagem acima, termina essa consideração sobre a especificidade do valorar frente ao prezar, desejar, querer, com a seguinte pergunta: “Como cabe, porém, esclarecer essa diferença?” Essa pergunta de Husserl, no contexto em que ocorre, tem um vibração de exasperação, pois Husserl parece se dar conta, nesse ponto, de que ele pode ver bem como se comportam fenomenologicamente as moções do ânimo, mas não sabe bem como lidar com a vivência de valorar que ele, no entanto, tão enfaticamente defende em sua especificidade não só frente ao representar, como ele sempre fizera, mas agora também frente ao prezar, desejar e querer; vivências estas que ele inicialmente, decerto influenciado por Brentano, sempre tratara como sendo os próprios modos de efetuação do valorar, como sendo o próprio valorar. Visto professar agora a especificidade do valorar como tal, cabe ao fenomenólogo caracterizar o que o valorar tem de específico frente ao mero representar e às meras moções do ânimo (sentimento, desejo, vontade).

A importância para Husserl de estabelecer essa diferença específica da valoração em relação às moções do ânimo não diz respeito apenas ao desdobramento consequente das análises fenomenológicas que se propõem a descrever a essência de todos os modos de consciência da vida intencional como tal, portanto, também da consciência valorativa. Isso decerto o motiva, mas há também uma razão sistemática para essa preocupação de Husserl, uma vez que, já nos Prolegômenos à Lógica Pura (HUSSERL, 1900; $2^{\circ}$ capítulo), Husserl esclarecera que prescrições de obrigações (tais como: "ao julgar, siga sempre o princípio de não-contradição") se fundam em normas (tais como: "um juízo deve excluir o juízo que lhe contradiz"), normas estas cuja validez depende de uma valoração básica (tal como: "somente um juízo não-contraditório é um bom juízo, isto é, um juízo correto ou um juízo em sentido próprio"). Ora, se a valoração que estabelece a norma da qual são derivadas prescrições práticas for uma valoração dependente de moções do 
ânimo e, portanto, dependente de apreciações interessadas (relativas ao sujeito) quanto ao agradável, desejável ou querível, então a norma não estará fundada objetivamente, não terá incondicionalidade estrita e, por conseguinte, a prescrição prática que ela gera não terá a força de estabelecer uma autêntica obrigação. $\mathrm{O}$ argumento de Husserl aqui é o de que uma prescrição se justifica pela norma que lhe dá a força de uma obrigação, enquanto a própria norma, por sua vez, se justifica com base no valor que ela promove. É bastante intuitivo que se alguém pede a justificação da norma que lhe estabelece uma obrigação, a única resposta realmente satisfatória estará em dizer: "você está obrigado a fazer isso porque isso é bom". Contudo, se "bom" tiver aí o sentido de agradável, desejável ou querível, então podemos sempre divergir quanto ao bom, e isso em função das diferentes moções do ânimo que nos animam.

Como se vê, o esclarecimento husserliano da natureza da normatividade (que é central para sua concepção de que as proposições lógicas idealmente objetivas podem ser parafraseada em normas incondicionais do julgar correto e, assim, em "leis do pensamento") supõe que valores sejam independentes dessa relação às moções do ânimo e, por conseguinte, que sejam objetivos, porquanto constituídos em vivências que não tem o caráter de apreciações interessadas subjetivas, mas antes em vivências específicas de valoração que constituem o valor como tal e não o meramente agradável ou desejável ou querível. Daí a insistência com que Husserl retoma o tema de uma axiologia analítica ou formal fundada fenomenologicamente em uma análise intencional da razão valorativa enquanto distinta não só da razão teórica, mas também da razão prática (que diz respeito, está sim, às moções do ânimo que motivam resoluções e ações). Esclarecer a especificidade dos atos valorativos (da classe da razão axiológica) é condição para garantir a objetividade dos valores que, por sua vez, é o pressuposto para toda ciência normativa (tal como pode ser o caso da lógica enquanto "arte" de pensar corretamente) que possa embasar prescrições de obrigações no plano então da razão prática. Como se vê, não é só a completude da fenomenologia que nos obriga a analisar descritivamente a especificidade dos atos de valoração que constituem propriamente valores, mas também o programa de uma axiologia analítica que é o pressuposto de uma fundamentação da razão prática e, portanto, da moralidade.

Cabe agora uma recapitulação para finalizar: Inicialmente, Husserl considera a vivência concreta de valoração como tendo uma estrutura bipartite: (i) um ato objetivante que representa um objeto e, fundado sobre ele, (ii) um ato apreciativo de tomar posição (subjetivamente) interessada com respeito ao objeto posto e, assim, constituí-lo como objeto-agradável, objeto-desejável, objetoquerível. Posteriormente, Husserl propõe uma estrutura tripartite na descrição da vivência concreta de valoração, a saber: (i) um ato objetivante que representa um objeto puro e simples, (ii) um ato de 
tomada de posição valorativa que constitui o objeto posto como objeto-valioso e, por fim, (iii) um ato interessado de apreciação do objeto-valioso como agradável ou não, desejável ou não, querível ou não. Com isso fica claro que, em sua reflexão mais madura, Husserl entende que não são nossos atos de gostar, desejar, querer que decidem pelo valor do objeto, mas antes tais atos já pressupõem um objeto-valioso pelo qual se interessarem, e tal objeto-valioso precisa ser então constituído por uma ato específico de valoração que (para não incorrermos em circularidade) não pode depender de moções do ânimo, ainda que possa e até precise pressupor atos de representação que ponha um objeto puro e simples à disposição do ato de valoração.

Considerando esse estado da questão, cabe dizer que, de fato, a fenomenologia avançou bastante na descrição da estrutura de vivências objetivantes ou representações, tais como perceber, imaginar, julgar, bem como avançou um pouco na descrição de vivências que são moções do ânimo, tais como gostar, desejar e querer, mas a fenomenologia decerto ainda nem bem começou o trabalho de análise descritiva da especificidade desses atos de valoração que, em suas notas criticas às Preleções de 1914, Husserl apenas vislumbrou sem, no entanto, nos dar mais do que rudimentos que possam contribuir para continuarmos seu trabalho. De todo modo, o que tentei aqui foi somente explicitar ao menos alguns desses rudimentos de Husserl que possam não só nos estimular a retomar suas análises da valoração, mas, sobretudo, que possam nortear o nosso trabalho futuro de uma descrição fenomenológica da especificidade da vivência de valoração. 
Notas:

1 Professor Adjunto do Departamento de Filosofia da Universidade Federal do Estado do Rio de Janeiro (UNIRIO), Brasil.

2 Para maiores detalhes sobre esse programa crítico husserliano cf. TEIXEIRA, 2007.

3 Para maiores detalhes sobre essa concepção subjetivista cf. TEIXEIRA, 2010.

4 "[Es gibt] Gegenstandlichkeiten, die Werte haben, aber in ihnen selbst liegt kein Pradikat, das da , gut“, „schon“ etc. heist. (...). Es ware eine evidente metabasis aus ihnen [sc. 'theoretische' Prädikate] Wertpradikate deduzieren zu wollen. Naturlich mussen wir aber der psychologistischen Versuchung widerstehen, Werte als psychische Pradikate anzusehen, als psychologische Objekte, und sie damit psychologistisch zu verfluchtigen. Freilich, diese Versuchung hangt gerade mit den uns bewegenden Schwierigkeiten innig zusammen. Denn fragen wir nach der Konstitution der Wertgegenstandlichkeiten, so stosen wir auf die ratselhafte Funktion der wertenden Akte" (HUSSERL, 1908/09; p.283-84). Todas as traduções são de responsabilidade do autor.

5 Contra a rigidez dessa datação, cf. $\$ 37$ do Ideen I (1913), onde Husserl trata já o valorar como um ato em seu próprio direito frente a outros atos afins (nomeadamente: as moções do ânimo) que "costumam" ser chamados também de "valorativos", tais como o alegrar-se com algo, o amar algo, o querer algo: "Im Akte des Wertens aber sind wir dem Werte, im Akte der Freude dem Erfreulichen, im Akte der Liebe dem Geliebten, im Handeln der Handlung zugewendet, ohne all das zu erfassen" (p.76; meu grifo). O ponto em questão no todo desse $\$ 37$ é o da diferença entre intencionar/referir-se e apreender/atentar, portanto, entre intentionales Objekt e erfasstes Objekt; quanto a esse ponto Husserl afirma: "Sind wir in einem Aktes des Wertens auf eine Sache gerichtet, so ist die Richtung auf die Sache ein Achten auf sie, ein sie Erfassen; aber 'gerichtet' sind wir — nur nicht in erfassender Weise - auch auf den Wert. Nicht bloss das Sachvorstellen, sondern auch das es umschliessende Sachwerten hat den Modus Aktualität" (Ideen I, §37, p.76[66-67]).

6 Pode-se querer retrucar que alegria também é uma vivência por assim dizer descomprometida ou sem relação com objetos determinados, por exemplo, no caso de se estar simplesmente alegre sem ter um porquê. Nesse caso, a alegria está sendo tomada decerto como uma vivência do sujeito (uma modificação em seu estado de ânimo: sentirse eufórico), mas não como intencional, isto é, não como devidamente motivada pela apreensão de algo, o que é o caso de vivências tais como o agradável (ou desagradável!) entorpecimento que sentimos no limiar do sono; enfim, estaremos equiparando a alegria/tristeza a uma mera afecção de prazer/desprazer que, de fato, não é intencional sem mais.

7 "Werten ist auch „Bewußtsein“ und nicht bloß Vorstellen, Wahrnehmen, Urteilen und dergl., und es ist wertendes und nicht denkendes oder wahrnehmendes Bewußtsein. Als wertendes Bewußtsein soll es für Objektivität, und zwar ihm wesentlich zugehörige Objektivität konstituierendes sein. (...). Es ist zweifellos, daß als Bewußtsein das Werten in seinen verschiedenen Formen, als Gefallen, als Wünschen, als Wollen, den Akten, die wir Wahrnehmen, Denken, Vermuten und dergl. nennen, gleichsteht, daß es seine differenzierten Beziehungsweisen auf Objektitäten hat" (HUSSERL, 1908/9; p.266).

8 "Die Frage ist, ob das „Daß A ist, ist gut“ $<$ bzw $>$ „Daß A ist, ist ungut“ gleichwertig ist mit „Daß A ist, ist erfreulich“ $<$ bzw $>$ „Daß A ist, ist unerfreulich“. In den Vorlesungen habe ich beides identifiziert. Aber man muß es sorgsam überlegen, ob mit Recht. Ich neigte wiederholt zu der Ansicht (und so auch jetzt wieder!), daß hier zu scheiden sei" (HUSSERL, 1914; p.155).

9 "Die sittliche Sachlage und die darauf bezogenen Gemutsbewegungen, das ist alles, was zum Werturteil notig ist; und doch ist es kein Urteil, das den Charakter der subjektiven Geltung hat, das von meinem Fühlen in diesem Augenblick etwas aussagt, sondern das objektiv und unbedingt allgemeingultig sein will und sagt: Das ist recht und gut" (HUSSERL, 1902; p.388).

10 No máximo, iríamos do individualmente subjetivo ao coletivamente subjetivo se tentássemos contornar essas críticas apenas por apelar a tais preferências (como o faz Hume) segundo as uniformidades genéricas nos modos de sentir (agrado/desagrado) dos sujeitos por força ou de pertencerem eles a uma mesma espécie natural ou a um mesmo grupo cultural: "Die Allgemeinheit einer Tatsache ist doch nicht die Allgemeinheit einer berechtigten Geltung” (HUSSERL, 1902; p.388). Sem contar que faz pleno sentido que a tendência normal 
(biologicamente/psicologicamente) dos espécimes medianos da espécie humana se defronte com um modo de sentir e de aprovar/desaprovar completamente discrepante ou anormal e mesmo assim o reconheça como efetiva valoração e até como uma valoração correta que nos impõe revisões em nosso standard de valoração: "Und doch meinen wir, daß diese einzelnen entgegen der ganzen Welt die richtige, und einzig richtige Wertschätzung vollzogen haben mögen: Christus gegen die ganze antike Welt" (idem; p.388-9). Ademais, esse conhecimento factual acerca de tais uniformidades é, em termos fenomenológicos, essencialmente irrelevante para uma valoração: "Meint man, die Allgemeingültigkeit der moralischen Beurteilung entspringe hier aus der Allgemeinheit dieser Fühlweise, so werden wir doch sagen: Von dieser Allgemeinheit wissen wir nicht. Sie geht uns auch gar nichts an. Es ist mir völlig gleichgültig, ob ausser mir jemand sonst so $\mathrm{zu}$ fühlen und danach so $\mathrm{zu}$ urteilen, sittlich zu schätzen vermag. und wenn die ganze Welt mit psychologischer Notwendigkeit anders schätzte: ich schaue es, ich erlebe es" (idem; p.388).

11 "Der Wert der gemütswarmen Akte hängt ab von dem Wert der Ziele, auf die sie sich richten (nur sie sind abzielend). Werte ich etwas als gut, so ist die Freude daran berechtigt bzw. der Wunsch danach etc. berechtigt. Aber kann ich dann sagen, daß jedes Sich-Freucn, jedes Wünschen ein Werten impliziere? Hier also ist die Untersuchung anzusetzen" (HUSSERL, 1914b; p.156).

12 "Das ästhetische Werten: Das originäre Bewußtsein vom Schönen und Häßlichen war das Motiv, der Grund der Freude am Sein, des ästhetischen Entzückens, des ästhetischen Abgestoßenseins etc. Das Für-unwert-Halten ist nicht selbst ein Abgestoßensein, ebensowenig wie das ästhetische Für-wert-Halten ein Angezogensein ist. Es begründet aber ein solches. Auch Freude, satte Freude, die nicht als erfüllende eintritt, ist Angezogensein, aber von vornherein schon ganz dabeiseiend. Wenn ich müde bin, kann ich mich nicht mehr freuen (Bildergalerie) oder nur sehr schwach freuen, aber die Wertungen ändern sich nicht. Die haben gar keine Intensität, sie haben nur Unterschiede des 'höherwert' und 'minderwert'" (HUSSERL, 1914b; p.156).

13 "Das Werten ist aber kein Langen und Zufriedensein als bloßer Endmodus des Langens im Sinne der Freude. Das „Interessiertsein“ der Freude und Trauer, der Hoffnung und Furcht, des Wünschens in all seinen Formen und des Wollens gar, das ist etwas ganz anderes als das Werten und sein Wertend-in-Rechnung-Ziehen Existenz oder NichtExistenz. Die ersteren Akte sind im prägnanten Sinn abzielende bzw. terminierende, nicht aber das Werten. Wie ist aber der Unterschied zu klären?” (HUSSERL, 1914b; p.155). 


\section{Referências bibliográficas:}

HUSSERL, Edmund. (1988) Vorlesungen über Ethik und Wertlehre 1908-1914. Kluwer: Hua XXVIII.

. (1914a) "Vorlesungen über Grundfragen zur Ethik und Wertlehre". In:

Husserl, 1988.

. (1914b) "Schiefheiten in meiner Lehre von Werten in der Vorlesung über formale Axiologie un Praktik". In: Husserl, 1988.

Husserl, 1988.

. (1911) "Vorlesungen über Grundprobleme der Ethik und Wertlehre". In:

. (1908/09). "Vorlesungen über Grundprobleme der Ethik". In: Husserl, 1988.

. (1902). "Die Gefühlsgrundlage der Moral. Zur Auseinandersetzung mit Humes Moralphilosophie". In: Husserl, 1988.

. (1900) Logische Untersuchungen. I. Band: Prolegomena zur reinen Logik. Felix Meiner: Gesammelte Schriften 2, 1992.

. (1901) Logische Untersuchungen. II. Band; I. Teil; Untersuchung V: "Über intentionale Erlebnisse und ihre 'Inhalte'". Felix Meiner: Gesammelte Schriften 3, 1992.

HUME, David. (1987) A Treatise of Human Nature. Oxford: Clarendon Press.

TEIXEIRA, Dario. (2007) "O Relativismo criticado pela Fenomenologia". In: Ethica, vol.14, nº1, 2007.

. (2010) "Hume e a valoração a partir dos outros". In: Costa, A. et al (eds). Ética e Alteridade. RJ: EDUR, 2010; p.01-18. 